\title{
Formulation Development and Characterization of Nanoemulsion-based Gel for Topical Application of Raloxifene Hydrochloride
}

\author{
Tej Pratap Singh ${ }^{1, \star}$, Farhan Jalees Ahmad², Gaurav Kumar Jain ${ }^{3}$, Navneet Verma ${ }^{4}$ \\ ${ }^{1}$ School of Pharmaceutical Sciences, IFTM University, Moradabad, Uttar Pradesh, INDIA. \\ 2Department of Pharmaceutics, School of Pharmaceutical Education and Research, Jamia Hamdard, New Delhi, INDIA. \\ ${ }^{3}$ Department of Pharmaceutics, Delhi Pharmaceutical Science and Research University, New Delhi, INDIA. \\ ${ }^{4}$ Pharmacy Academy, IFTM University, Moradabad, Uttar Pradesh, INDIA.
}

\begin{abstract}
Background: Nanoemulsion-gels are nanosized droplets, and thermodynamically stable oil-in-water dispersion. Raloxifene hydrochloride a selective estrogen receptor modulator currently its more research is being laid on in treatment of diseases in estrogen deficient postmenopausal women. Objectives: The objective of this research was to formulate nanoemulsion-gel of raloxifene for topical delivery. Materials and Methods: The oil, surfactant and cosurfactant were selected on the basis of maximal solubility of raloxifene. The screening of surfactant and cosurfactant were on the basis of their emulsification efficacy with oil to form homogenization mixture on gentle shaking. The nanoemulsions were prepared by ternary phase diagram method using different ratio of oil and surfactant-cosurfactant mixture $\left(S_{\text {mix }}\right)$ and nanoemulsion region obtained by excel sheet design triangular software. Results: The composition of the optimized nanoemulsion contains $0.072 \% \mathrm{w} / \mathrm{v}$ raloxifene, $14.29 \% \mathrm{v} / \mathrm{v}$ oil phase (Labrafil-M2125CS), 33.33\% v/v $\mathrm{S}_{\text {mix }}$ (Cremophor-RH40:Transcutol-P, $1: 1$ ), and $52.38 \% \mathrm{v} / \mathrm{v}$ distilled water. The optimized nanoemulsion was converted into gel form by addition of $1 \% \mathrm{w} / \mathrm{v}$ Carbopol-934. The formulation NEG2 possessed droplets size $56.73 \pm 0.58 \mathrm{~nm}$, zeta-potential $-22.20 \pm 0.02 \mathrm{mV}$, spreadability $18.35 \pm 0.45 \mathrm{gcm}^{-1} \mathrm{sec}^{-1}$ and viscosity $98.54 \pm 0.39$ mPas. The ex vivo permeation of NEG2 (22.38\%) was comparatively lower to the permeation of NE3 (26.68\%). Also, flux of NEG2 $\left(11.96 \pm 0.4 \mu \mathrm{gcm}^{-2} \mathrm{~h}^{-1}\right)$ significantly lower permeability than NE3(16.28 $\left.\pm 0.7 \mu \mathrm{gcm}^{-2} \mathrm{~h}^{-1}\right)$. But nanoemulsion-gel form is maintained more effective concentration within skin due to adhesive nature of gel form remain contact on the applied area for a long duration. Nanoemulsion-gel found stable during six months. Conclusion: The outcome of this study points out the nanoemulsiongel better than nanoemulsion because of adhesive nature and less permeability. Consequently, It maintain more raloxifene concentration at applied skin.
\end{abstract}

Key words: Raloxifene hydrochloride, Nanoemulsion gel, Ternary phase diagram, Zeta potential, Permeation.

\section{INTRODUCTION}

Raloxifene hydrochloride (RLX) is the selective estrogen receptor modulator used in the management of osteoporosis and invasive breast cancer in postmenopausal women. RLX exert tissue specific estrogenic (agonist) effects on bone tissues and antiestrogenic (antagonist) effects on mammary and uterine tissues. ${ }^{1}$ In the treatment of osteoporosis and breast cancer in post- menopausal women ${ }^{2}$ the oral delivery of RLX in tablet form have limited therapeutic efficacy because of insolubility in aqueous phase and very low bioavailability only $2 \%$ due to extensive hepatic first-pass metabolism. ${ }^{3}$ It's also has proven effect in management of wound healing in postmenopausal women. ${ }^{4-6}$ Interestingly, RLX loaded nanoemulsion gel (NE-
Submission Date: 12-06-21; Revision Date: 18-08-21; Accepted Date: 10-09-21

DOI: 10.5530/ijper.55.4.200 Correspondence: Mr. Tej Pratap Singh, School of Pharmaceutical Sciences, IFTM University, Moradabad-244102, Uttar Pradesh, INDIA Phone: +91-8265863537, Email - tej.ptp@gmail.com

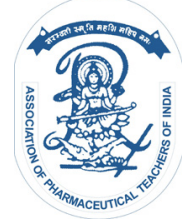

www.ijper.org 
gel) selectively applied topically for target location in the management of wound healing in postmenopausal women, because of due to minimization of metabolic drug decomposition, improve bioavailability of RLX, reduced systemic side effect, penetrate the stratum corneum and remain intact within the skin. Topical delivery of the RLX shows epidermal localization, which could induce healing of the wounded skin more efficiently as compare to other dosage form of RLX.?

Nanoemulsions (NEs) are thermodynamically stable and isotopically transparent dispersions of two immiscible liquids, such as an oil and a water phase in a combination with a surfactant and a cosurfactant. ${ }^{8}$ The mean diameter of the dispersed phase is usually in the range of $20-500 \mathrm{~nm}$. Reducing droplet size to the nanoscale level leads to an improvement in physical properties, such as optical transparency, long-term thermodynamic stability, solubilization capacity, and it induces Brownian motion and reduces destabilization limits such as Ostwald ripening and coalescence, creaming, and sedimentation. ${ }^{8,9}$ NEs have also become very commercially attractive for various drug delivery dosage forms, such as creams, gels, liquids, sprays, aerosols, and foams, and can be administered topically, orally, nasally, intravenously, pulmonary, ocularly and through other body cavities. ${ }^{10}$ In topical delivery, the drug has to act on the skin or within the epidermis. RLX, as a lipophilic drug, can permeate easily through the lipid layers of the skin. NE faces disadvanges of low viscosity related spreadability and poor retention on the skin. ${ }^{11}$ Such disadvantages restrict the nanoemulsion platform for topical application. Therefore, to overcome this problems nanoemulsion converted into nanoemulsion gel form. ${ }^{12}$ As NE-gel form has better adhesive property on the skin surface and high drug dissolving capability, it uphold adequate concentration gradient of drug towards the skin and provide better skin penetration.

\section{MATERIALS AND METHODS}

\section{Materials}

Raloxifene hydrochloride was a gift sample from Cadila Pharma (Ahmedabad, Gujarat, India). Methanol, propylene glycol and Carbopol 934 were obtained from SD Fine Chemicals, Mumbai, acetonitrile, Isopropyl myristate and triacetin were obtained from E-Merck, Mumbai. Labrafil M2125CS, Caproyl 90, Labrasol,Cremophor RH40, propylene glycol and
Transcutol P were obtained as a gift from Gattefosse, India. All other chemicals used in this research were of analytical grade.

\section{Methods}

\section{Drug solubility studies}

Solubility of RLX in different components i.e., oils, surfactants, and cosurfactants is the first criteria for a effective NE formulation. Its solubility was determined by dissolving an excess amount of RLX in $2 \mathrm{ml}$ of each of the oils, surfactants, and cosurfactants in a $5 \mathrm{ml}$ stoppered vial, followed by vortex mixing for $30 \mathrm{~s}$. Mixtures were shaken for $72 \mathrm{hr}$ at $37 \pm 1^{\circ} \mathrm{C}$ in a thermostatically controlled shaking water bath, after which they were centrifuged using Remi R-8C centrifuge, Mumbai at $5000 \mathrm{rpm}$ (with rotor diameter, $16 \mathrm{~cm}$ ) for $10 \mathrm{~min}$. The supernatant was separated using a $0.45 \mu \mathrm{m}$ membrane filter. Filtrates were then diluted with methanol and the solubility of RLX was determined by measuring its concentration spectrophotometrically (UV-160A; Shimadzu, Kyoto, Japan) at $289 \mathrm{~nm}$. Experiments were done in triplicates. ${ }^{2,13-15}$

\section{Screening of surfactants}

Emulsification efficiency of surfactants (Acconon CC6, Akrysol K140, Cremophor EL, Cremophor RH40, Labrasol, Span 20, Span 80, Tween 20, and Tween 80) with oils was determined based on the transmittance percentage and the number of flask inversions. The surfactant-oil mixtures were slowly heated to $50^{\circ} \mathrm{C}$ to homogenize the components. Then, dilute the $50 \mathrm{mg}$ of each surfactant-oil mixture with distilled water to $50 \mathrm{ml}$ in a stoppered conical flask. The emulsification efficiency was determined by the number of flask inversions required to yield a homogeneous emulsion. After $2 \mathrm{hr}$, the transmittance percentage was measured at $638 \mathrm{~nm}$ with distilled water as the reference. Development of turbidity or phase separation was inspected visually., ${ }^{2,16-18}$

\section{Screening of cosurfactants}

Emulsification efficiency of cosurfactants poly ethylene glycol (PEG 200, PEG 400), propylene glycol, isopropyl alcohol, and Transcutol $\mathrm{P}$ in saturated RLX solutions was evaluated using the oil phase and the surfactant chosen from the preliminary screening. Mixture preparation (Surfactant-cosurfactant mixtures $\left(\mathrm{S}_{\text {mix }}\right)$, with rations 4:1, 3:1, 2:1, 1:1, 1:2, 1:3 and oil phase) and its assessment followed a similar pattern to described in the surfactant screening section. ${ }^{2}$ 


\section{Optimization of components using the ternary phase diagram}

Formations of NE were detected using the ternary phase diagram, with different ratios of oil to $S_{\text {mix }}$. Also, the drug effect on the phase diagram of the selected systems was studied. According to maximal solubility of drug, Labrafil M2125CS (HLB 4) was selected as the oil phase, Cremophor RH40 (HLB 14) was selected as the surfactant, and Transcutol P (HLB 4.3), was selected as the cosurfactant, and distilled water was used as the aqueous phase. $S_{\text {mix }}$ in rations 1:0, 4:1, 3:1, 2:1, 1:1, 1:2, 1:3 were chosen, and for each ternary phase diagram, the oil and a specific $S_{\text {mix }}$ ratio was mixed thoroughly in different volume ratios from $1: 9$ to $9: 1$, with sixteen different combinations $(1: 9,1: 8,1: 7,1: 6,1: 5,2: 8,1: 3.5$, $1: 3,3: 7,1: 2,4: 6,5: 5,6: 4,7: 3,8: 2,9: 1)$ to cover a range of possible combinations in the ternary phase diagram. The ternary phase diagrams were obtained by the aqueous titration method. Titration with distilled water was performed for each mass ratio of the oil and $S_{\text {mix }}$ systems by visually observing the flow and transparency of the NEs. Ternary phase diagrams were constructed from the obtained titration values with axes representing phase components. The regions of NEs were obtained by the excel sheet design triangular software.

\section{Stability studies of optimized nanoemulsions Centrifugation}

The selected formulations were centrifuged by the aforementioned centrifuge at $5000 \mathrm{rpm}$ for $10 \mathrm{~min}$ to test the stability of formulations by detecting a potential separation of phases. Centrifugation was found to be the best method to detect stability of optimized NEs which do not undergo phase separation were chosen for the next stability testing method. ${ }^{19}$

\section{Thermal stability of nanoemulsions}

Thermal stability of NEs was determined by placing NEs in a $10 \mathrm{ml}$ transparent borosilicate volumetric flask at three different temperatures i.e., 4, 25, and $45 \pm 1^{\circ} \mathrm{C}$ in an incubator for $48-72 \mathrm{hr}$. NEs that did not undergo physical changes such as loss of coalescence, clarity, and turbidity were chosen for the next stability testing method. ${ }^{20}$

\section{The freeze-thaw method}

The freeze-thaw method was used with the temperature ranging from -4 to $4{ }^{\circ} \mathrm{C}$ for $24 \mathrm{hr}$. Samples were periodically checked visually for any physical changes in clarity, coalescence and turbidity. ${ }^{20}$

\section{Dispersibility test}

The dispersibility test was conducted using the XXII USP dissolution apparatus. Infinite dilution of the test sample was made in $900 \mathrm{ml}$ of distilled water and $0.1 \mathrm{M}$ $\mathrm{HCl}$ at $37 \pm 1^{\circ} \mathrm{C}$ and dilutions were checked by the dissolution apparatus. ${ }^{21}$

\section{Percentage of transmittance}

Percentage of transmittance $(\% \mathrm{~T})$ was measured by diluting $1 \mathrm{ml}$ of the formulations with distilled water to $100 \mathrm{ml}$ and measuring transmittance Table 1 at 650 $\mathrm{nm}$. Formulations with $\% \mathrm{~T}>99 \%$ were considered stable and were used for further investigation. ${ }^{22}$

\section{Formulation of nanoemulsions and their gels}

The RLX stock solutions were prepared by dissolving $50 \mathrm{mg}$ of the drug in $10 \mathrm{ml}$ of the oil mixture (oil, $\mathrm{S}_{\text {mix }}$, and water), after which $0.5,1.0,1.5$, and $2 \mathrm{ml}$ of these stock solutions were transferred to four different test tubes, respectively, and the oil mixture was added to the final volume of $10 \mathrm{ml}$ for the final oil percentages of $5 \%, 10 \%, 15 \%$, and $20 \%$, respectively.

With the ternary phase diagram having been constructed, the different formulations were selected at different points from the phase diagram which confirmed the drug doses with regards to the drug solubility in the oil phase. It was determined that approximately $5 \mathrm{mg}$ of RLX can be solubilized in $1 \mathrm{ml}$ of Labrafil M2125CS (Figure 1). Therefore, in $10 \mathrm{ml}$ of prepared formulations with $5 \%, 10 \%, 15 \%$, and $20 \%$ Labrafil M2125CS containing $2.5 \mathrm{mg}, 5.0 \mathrm{mg}, 7.5 \mathrm{mg}$, and $10 \mathrm{mg}$ of RLX respectively. The selected NE regions with the incorporated drug in the range from 1.25 to $2.5 \mathrm{mg}$ and the oil percentage is $5 \%, 10 \%, 15 \%$, or $20 \%$. Also, for each formulation the minimum concentration of $S_{\text {mix }}$ was used.

Selected formulations NE2, NE3, and NE5 Table 2 were converted into their gel forms NEG1, NEG2, and NEG3 respectively according to an established method ${ }^{23}$ to enhance their bioadhesive strength and their long-term

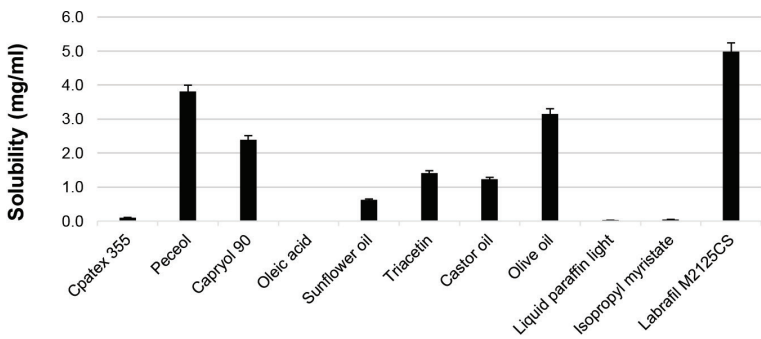

Figure 1: The solubility of raloxifene hydrochloride in different oils. 


\begin{tabular}{|c|c|c|c|c|c|c|c|c|c|c|c|}
\hline \multirow{2}{*}{$S_{\text {mix }}$} & \multirow{2}{*}{ Oil: $\mathbf{S}_{\text {mix }}$} & \multirow{2}{*}{$\begin{array}{l}\text { Trial } \\
\text { Code }\end{array}$} & \multirow{2}{*}{ Oil (\%) } & \multirow{2}{*}{$\mathrm{S}_{\text {mix }}(\%)$} & \multicolumn{2}{|c|}{$\begin{array}{l}\text { Dispersibility } \\
\text { test (grade) }\end{array}$} & \multirow{2}{*}{$\begin{array}{c}\text { Dispersion } \\
\text { Grade }\end{array}$} & \multirow{2}{*}{$\begin{array}{c}\text { Appearance } \\
\text { after } 1 / 100 \\
\text { dilution }\end{array}$} & \multirow{2}{*}{$\begin{array}{l}\% \mathrm{~T} \pm \mathrm{SD} \\
\text { at } 650 \mathrm{~nm}\end{array}$} & \multirow{2}{*}{$\begin{array}{c}\% \mathrm{~T} \pm \mathrm{SD} \text { at } \\
650 \mathrm{~nm} \text { after } \\
\text { dilution }\end{array}$} & \multirow{2}{*}{ Inference } \\
\hline & & & & & Water & $\begin{array}{l}0.1 \mathrm{M} \\
\mathrm{HCl}\end{array}$ & & & & & \\
\hline \multirow{2}{*}{$2: 1$} & $1: 9$ & LCT 154 & 4.76 & 42.86 & A & A & A & Clear & $98.3 \pm 0.1$ & $97.2 \pm 0.3$ & Failed \\
\hline & $2: 8$ & LCT 174 & 8.70 & 34.78 & A & A & A & Clear & $99.4 \pm 0.1$ & $99.3 \pm 0.2$ & Passed \\
\hline \multirow{6}{*}{$1: 1$} & \multirow{3}{*}{$1: 9$} & LCT 229 & 4.55 & 40.91 & A & A & A & Turbid & Fail & Fail & Failed \\
\hline & & LCT 230 & 4.35 & 39.13 & B & A & A & Turbid & Fail & Fail & Failed \\
\hline & & LCT 231 & 4.17 & 37.50 & B & A & A & Turbid & Fail & Fail & Failed \\
\hline & \multirow{2}{*}{$2: 8$} & LCT 242 & 10.53 & 42.11 & A & A & A & Clear & $97.3 \pm 0.7$ & $98.1 \pm 0.2$ & Failed \\
\hline & & LCT 243 & 10.00 & 40.00 & A & A & A & Clear & $99.3 \pm 0.6$ & $99.5 \pm 0.1$ & Passed \\
\hline & $3: 7$ & LCT 260 & 14.29 & 33.33 & A & A & A & Clear & $99.3 \pm 0.4$ & $99.2 \pm 0.1$ & Passed \\
\hline \multirow{4}{*}{$1: 2$} & \multirow{2}{*}{$1: 9$} & LCT 312 & 4.17 & 37.50 & A & A & A & Clear & $98.1 \pm 0.1$ & $98.2 \pm 0.3$ & Failed \\
\hline & & LCT 313 & 4.00 & 36.00 & A & A & A & Clear & $99.3 \pm 0.4$ & $99.7 \pm 0.1$ & Passed \\
\hline & \multirow{2}{*}{$2: 8$} & LCT 330 & 9.52 & 38.10 & A & A & $A$ & Clear & $90.5 \pm 0.3$ & $87.4 \pm 0.1$ & Failed \\
\hline & & LCT 331 & 9.09 & 36.36 & $A$ & A & $A$ & Clear & $99.5 \pm 0.2$ & $99.6 \pm 0.3$ & Passed \\
\hline \multirow{2}{*}{$1: 3$} & \multirow{2}{*}{$1: 9$} & LCT 392 & 4.35 & 39.13 & A & $\mathrm{C}$ & $\mathrm{C}$ & Clear & $86.3 \pm 0.4$ & $82.5 \pm 0.2$ & Failed \\
\hline & & LCT 393 & 4.17 & 37.50 & A & $C$ & $C$ & Clear & $79.8 \pm 0.4$ & $78.7 \pm 0.5$ & Failed \\
\hline
\end{tabular}

Values of dispersibility represent in grades A: a clear nanoemulsion formed rapidly within one minute, B: a less clear nanoemulsion formed within one minute, C: a fine milky type nanoemulsion, D: a greyish, slightly oily nanoemulsion.

consistency on applied surfaces. The Carbopol 934 polymer was used as the gel matrix, which swelled with a small amount of water for $24 \mathrm{hr}$, resulting in a high viscosity solution. Selected NEs were then added 1\% w/w Carbopol 934 under constant stirring to form viscous NE-gels are given in Table 3.

\section{Characterization of nanoemulsions and their gels Microscopic evaluation}

Homogeneity of formulations was studied using Olympus Binocular CH-20i microscope. The purpose of this study was to find any changes in the appearance of the optimized formulations e.g., a change in color, transparency, or separation of phases that occurred during standard conditions at $37 \pm 2^{\circ} \mathrm{C}$.

\section{Nanoemulsion size analysis}

The formulations' particle size was determined using the Malvern Zetasizer version 6.20. It works on the principle of laser scattering, where a solid-state laser diode acts as a light source for evaluating the size of droplets by light scattering at $25^{\circ} \mathrm{C}$ at a $90^{\circ}$ angle. In this process, the optimized NEs samples of $0.5 \mathrm{ml}$ were diluted with $50 \mathrm{ml}$ of distilled water, placed in a quartz cuvette, and subjected to the droplet size analysis. ${ }^{24}$

\section{Droplet size distribution}

Droplet size distribution was determined by the photon correlation spectroscopy, which analyses fluctuations in light scattering due to the Brownian motion of the particles. Using the Malvern-Zetasizer, light scattering was monitored at $25^{\circ} \mathrm{C}$ at a $90^{\circ}$ angle. ${ }^{14}$

\section{Polydispersity index}

The polydispersity index is the ratio of the standard deviation and the mean droplets size and it shows if the droplets size is homogenous within the formulation. The lower polydispersity index represents higher homogeneity in droplets size in the formulation. ${ }^{25}$

\section{Zeta potential}

The zeta potential is an important parameter that provides information about the stability and indicates if a charge is present in the colloidal systems ${ }^{3}$ and its measurements were obtained using the Malvern Zetasizer. A highly negative or positive charge on the surface or the interface of oil droplets indicates higher stability because of the anticipated surface repulsion between similarly charged droplets, which inhibits their aggregation.

\section{Viscosity}

The viscosity of NEs and their gel forms were measured using the Brookfield viscometer LV DV-III ultra-rheometer, which can measure viscosity and shear stress at given shear rates. It consists of a water jacket, a sample holder, and a spindle. The viscosity range is achieved using several spindles over different rotational speeds. In this 
study, the sample holder was connected to the circulating water bath and the temperature was controlled by the temperature controller and a computer to monitor and save the measured data using the viscosity calculations software Rheocalc V2.6. ${ }^{21}$

\section{Refractive index}

Abbe-type refractometer AR-20, WESWOX, Ambala, Haryana was used to determine the refractive index of the optimized formulations. Castor oil was used to calibrate the refractometer. The measurements were performed in triplicates at $25^{\circ} \mathrm{C} .{ }^{20}$

\section{Conductivity measurements}

The conductivity of NEs was measured using a conductometer SE-980, Simtronics, Panchkula, Haryana equipped with a magnetic stirrer. The conductometer was fitted with two platinum plates at a certain distance from each other with a liquid between the two plates which acts as a conductor. In this way, the NE type and phase inversion phenomenon can be determined. ${ }^{26}$

\section{TEM analysis}

Morphology and nanostructure of NE was determined by TEM, Topcon 002B (Topcon, Tokyo, Japan) was used. The resolution of the instrument was $0.18 \mathrm{~nm}$. Bright-field imaging modes were used to determine the type and the particle size of the NEs. In TEM observations, first, $0.1 \mathrm{ml}$ of the NEs was diluted with distilled water to a final volume of $100 \mathrm{ml}$. A small drop of the diluted NE was then dropped on the 200-mesh copper grid and left for 2 min. After this, the grid was kept inverted and a drop of the phosphotungstic acid was added to the grid for $5 \mathrm{~s}$ and the excess of the phosphotungstic acid was removed by drying it in filtered air. The grid was kept under the Infra-red lamp for half an hour to dry and then it was analyzed using the instrument at $200 \mathrm{kV} .{ }^{14}$

\section{Spreadability}

A wooden block apparatus was employed to determine the spreadability of the formulations, which was measured using the "slip-and-drag" method. In this method, there is a pulley system at one end and a ground glass slide is fixed on the wooden block. An excess of NE-gel (around $2 \mathrm{~g}$ ) was placed on the ground slide. A weight of $100 \mathrm{~g}$ was put on the top of the two slides for $5 \mathrm{~min}$ to remove the trapped air and to provide a uniform gel film between the slides. The excess of the gel was then scrapped off the edges and the upper plate was subjected to a pull of a $20 \mathrm{~g}$ weight with the help of a string attached to the hook. The time required by the upper slide to cover the distance of $7.5 \mathrm{~cm}$ was measured. ${ }^{27-29}$ The following formula for spreadability was used:

$$
S=\frac{M \times L}{T}
$$

where $S$ is spreadability, $\mathrm{M}$ is the weight tied to the upper slide, $\mathrm{L}$ is the glass slide length, and $\mathrm{T}$ is the time needed to separate the slides from each other.

\section{Ex-vivo permeation}

Ex-vivo permeation studies of NEs (NE1-NE5) and NE-gel (NEG1-NEG3) were performed through rat skin by using a Franz diffusion apparatus (model EMFDC-07, Meditech Technologies, Chennai, India). Subsequent pre-treatment, the rat skin was cut and trimmed to suitable size and mounted on a Franz diffusion apparatus with an area of $3.14 \mathrm{~cm}^{2}$ and the receptor volume of $15 \mathrm{ml}$. The rat skin was mounted in between the donor and the receiver compartment in such a way where stratum corneum side of membrane faced the drug donor compartment and dermal side was in contact with receiver compartment of the Franz diffusion cell. The receiver compartment was filled with acetonitrile: monobasic phosphate buffer (APB) 7.4 (60:40, $V / V)$ and covered with aluminum foil. The whole assembly was placed in a thermostatically controlled shaker water bath and the temperature of the medium of $37 \pm 1^{\circ} \mathrm{C}$ was maintained. After application of optimized test formulations on the donor side, $2 \mathrm{~mL}$ of the samples was withdrawn from the receiver compartment at predetermined time intervals (viz. 0, $0.5,1,2,3,4,6,8,10$, and $12 \mathrm{~h}$ ) for $12 \mathrm{~h}$ period and the same volume of APB was added to replace the withdrawn volume. After appropriate dilutions, the withdrawn samples were filtered using a $0.45 \mu \mathrm{m}$ membrane filter and the amount of drug in receiver compartment was analyzed spectrophotometrically at $289 \mathrm{~nm}^{.15,21}$

\section{Skin permeability analysis}

The cumulative permeated drug $\left(\mathrm{mg} \mathrm{cm}^{-2}\right)$ was plotted depending on time. Drug flux (Jss) was obtained by dividing the slope with the diffusion cell area $\left(\mathrm{mg} \mathrm{cm}^{-2} \mathrm{~h}^{-1}\right)$, where the $\mathrm{x}$-intercept represents the lag time $\left(\mathrm{t}_{\mathrm{L}}, \mathrm{h}\right)$. Permeability coefficient $(K \mathrm{p})$ was obtained by dividing $J$ ss with the initial drug concentration in the donor cell $\left(\mathrm{cm} \mathrm{h}^{-1}\right) .^{14,15,21}$

$$
\mathrm{Jss}=\frac{\mathrm{Q}}{\mathrm{QT}}
$$




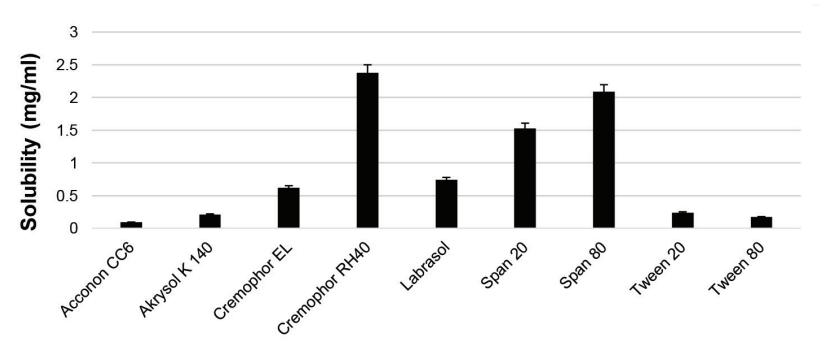

Figure 2: The solubility of raloxifene hydrochloride in different surfactants.

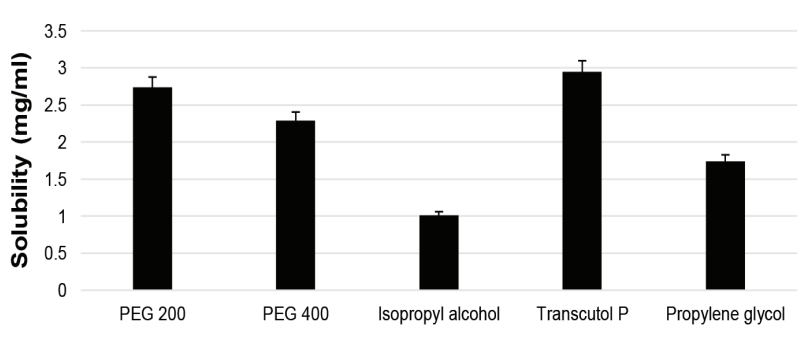

Figure 3: The solubility of raloxifene hydrochloride in different cosurfactants.

\begin{tabular}{|c|c|c|c|c|c|c|c|c|}
\hline \multirow{2}{*}{ Code } & \multirow{2}{*}{$\begin{array}{l}\text { Final } \\
\text { Code }\end{array}$} & \multirow{2}{*}{$\begin{array}{c}\text { Raloxifene } \\
\text { (mg) }\end{array}$} & \multirow{2}{*}{$\begin{array}{c}\text { Raloxifene } \\
(\% \mathrm{w} / \mathrm{v})\end{array}$} & \multicolumn{3}{|c|}{$\% v / v$} & \multirow{2}{*}{ Oil:S ${ }_{\text {mix }}$} & \multirow{2}{*}{$S_{\text {mix }}$} \\
\hline & & & & Oil & $S_{\text {mix }}$ & Water & & \\
\hline LCT 174 & NE1 & 4.35 & 0.044 & 8.70 & 34.78 & 56.52 & $2: 8$ & $2: 1$ \\
\hline LCT 243 & NE2 & 5.00 & 0.050 & 10.00 & 40.00 & 50.00 & $2: 8$ & \multirow{2}{*}{$1: 1$} \\
\hline LCT 260 & NE3 & 7.15 & 0.072 & 14.29 & 33.33 & 52.38 & $3: 7$ & \\
\hline LCT 313 & NE4 & 2.00 & 0.020 & 4.00 & 36.00 & 60.00 & $1: 9$ & \multirow{2}{*}{$1: 2$} \\
\hline LCT 331 & NE5 & 4.55 & 0.046 & 9.09 & 36.36 & 54.55 & $2: 8$ & \\
\hline
\end{tabular}

$$
\mathrm{Kp}=\frac{\mathrm{J} s \mathrm{~s}}{\mathrm{Cd}}
$$

where $J s s$ is the drug flux, $Q$ is the amount of the solute, $A$ is the area of the skin membrane, $T$ is the time, $K \mathrm{p}$ is the permeability coefficient, and $C d$ is the initial drug concentration.

\section{Stability studies}

The optimized batches NE2 and NE3 and their gel form NEG1 and NEG2 were used for stability studies. Formulations were transferred into ampules and placed into stability chambers following the $\mathrm{ICH}$ guidelines for two climatic conditions i.e., at $30^{\circ} \mathrm{C} / 65 \%$ relative humidity (RH) and the accelerated conditions at $40^{\circ} \mathrm{C} / 75 \% \mathrm{RH}$ for 6 months. It is considered that a sample stable at these conditions for at least 6 months will remain stable throughout their shelf life. ${ }^{29}$ Samples were taken at $0,1,3$, and 6 months to evaluate their zeta potential, droplet size, viscosity, refractive index, and accelerated centrifugation test. That prove the how the characteristics of formulation varies with time under the different environmental storage condition, such as temperature, humidity and light. ${ }^{18,23}$

\section{RESULTS AND DISCUSSION}

\section{Solubility studies and screening of excipients}

The saturation solubility studies of RLX were assessed in selected oily phases, surfactants and cosurfactants and their result as shown in Figure 1. Higher solubility of
RLX was found in nonionic oily phases as compare to ionicphases. As compare to the previous report ${ }^{2,3}$ that nonionic oily phases are copable of dissolving large amounts of lipophilic drugs. Solubility of RLX in oils phase Labrafil M2125CS was found to have maximum solubility $(4.99 \pm 0.27 \mathrm{mg} / \mathrm{ml})$. Based on these results, Labrafil M2125CS, Cremophor RH40 and Transcutol $\mathrm{P}$ were chosen for NE. Since RLX is lipophilic, we aim to formulate $\mathrm{o} / \mathrm{w}$ nanoemulsion. Hence the amount of drug incorporated in oily phase is an important criterion as poor soluble drugs needs more amounts of oil for maximum drug loading this will increase the cost of the formulajtion. Further, such a formulation will demand higher amounts of surfactants and cosurfactants blends to produce a stable nanoemulsion. For formulation of stable nanomeulsion the hydrophilic lipophilic balance (HLB) value of components Labrafil M2125CS (HLB 4), Cremophor RH40 (HLB 14) and Transcutol P (HLB 4.3) also an important factors as the blend with sufficient HLB value. ${ }^{30}$ In order to formulate $\mathrm{o} / \mathrm{w}$ nanoemulsion, the HLB value of selected surfactant mixture was more than 10 , which fulfills the criteria of minimum HLB value ${ }^{31}$ required for the stable oil-in-water nanoemulsion. The solublity of RLX in Cremophor RH40 is a hydrophilic and non -toxic surfactant was found to have higher solubility $(2.38 \pm 0.15 \mathrm{mg} / \mathrm{ml})$ as shown in Figure 2 was selected, and the cosurfactant Transcutol $\mathrm{P}$ have significant solubility $(2.95 \pm 0.25 \mathrm{mg} / \mathrm{ml})$ as shown in Figure 3 . 

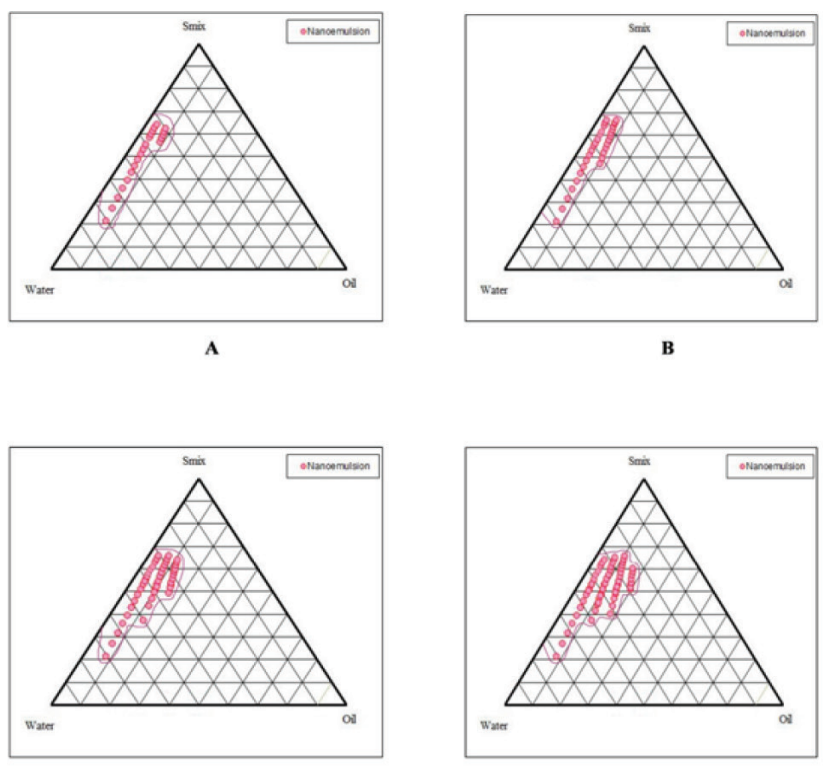

C

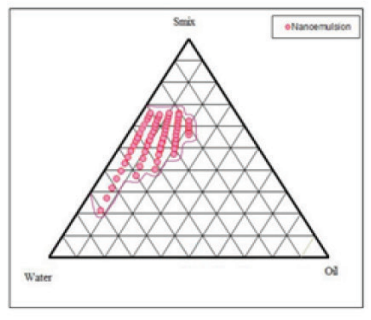

$\mathbf{E}$
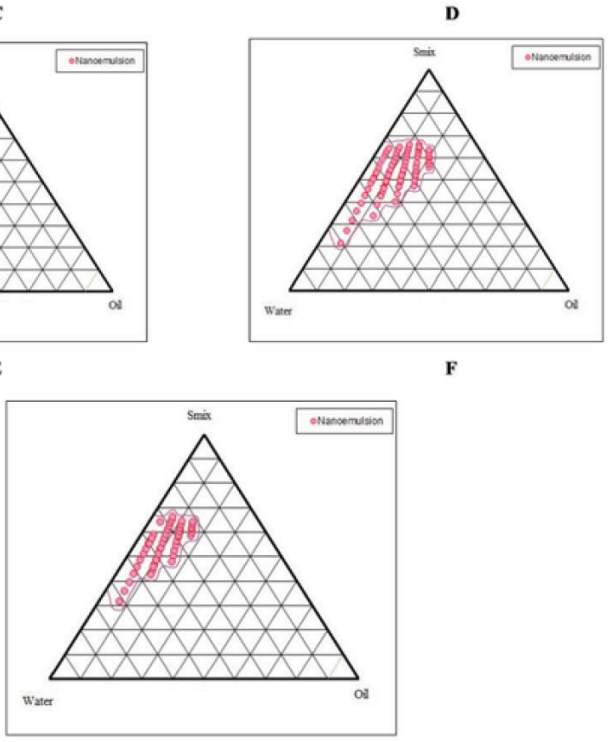

Figure 4: Ternary phase diagrams indicating oil-in-water nanoemulsion region of Labrafil M2125CS (oily phase) at different surfactant: cosurfactant $\left(S_{\text {mix }}\right)$ ratio: $A\left(S_{\text {mix }} 1: 0\right), B$ $\left(S_{\text {mix }} 4: 1\right), C\left(S_{\text {mix }} 3: 1\right), D\left(S_{\text {mix }} 2: 1\right), E\left(S_{\text {mix }} 1: 1\right), F\left(S_{\text {mix }} 1: 2\right)$, and $G\left(S_{\text {mix }} 1: 3\right)$. Dotted parts represent the nanoemulsion region.

\section{Optimization of components by the ternary phase diagram}

The NEs region depends on the concentration of the surfactant/cosurfactant ratio. Phase diagrams were constructed using- seven different combinations of $S_{\text {mix }} 1: 0,4: 1,3: 1,2: 1,1: 1,1: 2$ and 1:3. The percentage of oil solubility were $10 \% \mathrm{v} / \mathrm{v}$ in $23.33 \% \mathrm{v} / \mathrm{v}$ of $S_{\text {mix }}$ (1:0, 4:1), $13.33 \% \mathrm{v} / \mathrm{v}$ in $20 \% \mathrm{v} / \mathrm{v}$ of $S_{\text {mix }}(3: 1), 16.67 \% \mathrm{v} / \mathrm{v}$ in $16.67 \% \mathrm{v} / \mathrm{v}$ of $S_{\text {mix }}(2: 1), 20 \% \mathrm{v} / \mathrm{v}$ in $13.33 \% \mathrm{v} / \mathrm{v}$ of $S_{\text {mix }}(1: 1,1: 2)$, and $16 \% \mathrm{v} / \mathrm{v}$ in $16.67 \% \mathrm{v} / \mathrm{v}$ of $S_{\text {mix }}(1: 3)$ found to be increases with increasing the cosurfactant concentration. NE with oil of low RLX solubility would require more oil to incorporate in formulation to maintain the target RLX dose, which in turn $S_{\text {mix }}(1: 1)$ combination was selected to achieve required amount of oil solubility for formulation as given in Table 2 . This increase in the solubility of oil in water is due to greater penetration of the oil phase in the hydrophobic region of the surfactant monomers. ${ }^{32}$ Similarly, the ternary phase diagram also increases by increasing the cosurfactant concentration as shown in Figure 4. A shift towards region was observed, possibly due to a further reduction of the interfacial tension, which increased the fluidity of the interface, thereby increasing the entropy of the system. ${ }^{32}$ The ternary phase diagram $\mathrm{NE}$ region was evaluated for further optimization of the system. In Figure 4A a small area of NE region was observed when using Cremphor RH40 alone without cosurfactant (i.e., at $S_{\text {mix }}$ 1:0). When cosurfactant (Transcutol P) was added with Cremophor RH40 in lower concentration $\left(S_{\text {mix }}, 4: 1\right)$ further observed small area of NE region. Therefore, when the cosurfactant is absent or present at lower concentrations, the surfactant is not able to sufficiently reduce the oil-water interfacial tension. On further increasing the cosurfactant concentration, i.e., at $S_{\text {mix }}$ 3:1 and 2:1 (Figures 4C-D) the NE region increases as comparable to region $S_{\text {mix }}$ 1:0 and $S_{\text {mix }} 4: 1$. When cosurfactant was added with surfactant in equal amounts $\left(\mathrm{S}_{\text {mix, }} 1: 1\right)$ and slightly higher amount $\left(S_{\text {mix }} 1: 2\right)$, a higher $N E$ regions were observed (Figures 4E-F) and consequently further reduction of the interfacial tension and increased fluidity of the interface. When the surfactant concentration was further increased in the $S_{\text {mix }}$ ration of 1:3 as shown in Figure 4G, a decrease in the NE region was observed when compared with $S_{\text {mix }} 1: 1$ and 1:2. It can be concluded that, when Transcutol P concentration was increased in comparison to Cremophor RH40, the NE region increased up to the $1: 2 S_{\text {mix }}$ ratio, but $1: 3$ ratio, it was decreased, indicating that the optimum emulsification has been achieved.

\section{Thermodynamic stability and microscopic evaluation}

NEs are thermodynamically stable and are formed at particular concentrations of components, without creaming, cracking or phase separation. The optimized NEs were subjected to different conditions by applying a heating-cooling cycle, centrifugation, and the freezethaw procedure to test their thermodynamic stability. The formulations which passed the thermodynamic stability tests were namely 8.7:34.78:56.52 (2:1), 10:40:50 (1:1), 14.29:33.33:52.38 (1:1), 4:36:60 (1:2) and 


\begin{tabular}{|c|c|c|c|c|c|c|c|c|}
\hline \multirow{2}{*}{ Code } & \multirow{2}{*}{ Final Code } & \multirow{2}{*}{$\begin{array}{c}\text { Carbopol } 934 \\
(\% \mathrm{w} / \mathrm{v})\end{array}$} & \multirow{2}{*}{$\begin{array}{l}\text { Raloxifene } \\
(\% \mathrm{w} / \mathrm{v})\end{array}$} & \multicolumn{3}{|c|}{$\% \mathrm{v} / \mathrm{v}$} & \multirow{2}{*}{ Oil:S ${ }_{\text {mix }}$} & \multirow{2}{*}{$S_{\text {mix }}$} \\
\hline & & & & Oil & $\mathbf{S}_{\text {mix }}$ & Water & & \\
\hline NE2 & NEG1 & 1 & 0.050 & 10.00 & 40.00 & 50.00 & $2: 8$ & \multirow{2}{*}{$1: 1$} \\
\hline NE3 & NEG2 & 1 & 0.072 & 14.29 & 33.33 & 52.38 & $3: 7$ & \\
\hline NE5 & NEG3 & 1 & 0.046 & 9.09 & 36.36 & 54.55 & $2: 8$ & $1: 2$ \\
\hline
\end{tabular}

\begin{tabular}{|c|c|c|c|c|c|c|}
\hline \multicolumn{2}{|c|}{ Table 4: Droplet size, polydispersity index, zeta potential and conductivity data of nanoemulsions. } \\
\hline $\begin{array}{c}\text { Formulation } \\
\text { code }\end{array}$ & $\begin{array}{c}\text { Droplet size (nm) } \\
\text { mean } \pm \text { SD }\end{array}$ & $\begin{array}{c}\text { Polydispersity } \\
\text { index mean } \pm \text { SD }\end{array}$ & $\begin{array}{c}\text { Zeta potential }(\mathbf{m V}) \\
\text { mean } \pm \text { SD }\end{array}$ & $\begin{array}{c}\text { Conductivity } \\
(\boldsymbol{\mu S} / \mathbf{c m}) \pm \text { SD }\end{array}$ & $\begin{array}{c}\text { Viscosity } \\
(\mathbf{m P a} \cdot \mathbf{s}) \\
\text { mean } \pm \text { SD }\end{array}$ & $\begin{array}{c}\text { Refractive } \\
\text { index } \\
\text { mean } \pm \text { SD }\end{array}$ \\
\hline NE1 & $35.02 \pm 0.23$ & $0.87 \pm 0.12$ & $-4.02 \pm 0.23$ & $122.3 \pm 2.3$ & $64.02 \pm 0.18$ & $1.47 \pm 0.05$ \\
\hline NE2 & $70.21 \pm 0.16$ & $0.21 \pm 0.03$ & $-22.50 \pm 0.15$ & $136.1 \pm 1.5$ & $80.22 \pm 0.78$ & $1.93 \pm 0.05$ \\
\hline NE3 & $78.09 \pm 0.11$ & $0.34 \pm 0.05$ & $-23.20 \pm 0.52$ & $127.0 \pm 4.7$ & $78.19 \pm 0.33$ & $1.81 \pm 0.02$ \\
\hline NE4 & $39.42 \pm 0.83$ & $0.89 \pm 0.18$ & $-2.92 \pm 0.42$ & $189.2 \pm 3.4$ & $49.68 \pm 0.76$ & $1.11 \pm 0.03$ \\
\hline NE5 & $82.62 \pm 0.29$ & $0.29 \pm 0.08$ & $-17.50 \pm 0.73$ & $144.2 \pm 3.2$ & $70.12 \pm 0.35$ & $1.75 \pm 0.05$ \\
\hline
\end{tabular}

Values represented as mean \pm standard deviation (SD), $n=3$

9.09:36.36:54:55 (1:2); these were then coded as NE1, NE2, NE3, NE4 and NE5 respectively (Table 2). Finally, five formulations (NE1-NE5) were selected based on their uniform dispersibility, color, transparency and no phase separation as given in Table 1 . These were also the ones that contained minimum amount of surfactant which is a major criteriaon for selection of such formulations. The rest of formulations showed phase separation, change in color, turbidity suggest instability and were rejected.

\section{Characterization of nanoemulsions and their gels}

The droplets sizes of RLX-NEs and its gel were in the nanosized range as given in Table 4-5. The droplet size increased according to increase of the oil concentration in the formulations. In the optimized formulations of NEs, $85 \%$ of the droplets sizes were below $100 \mathrm{~nm}$. The droplets size distribution of optimize batch NE3 show uniformity of droplets in dispersion medium. The droplet sizes and its distribution of optimize batch NEG2 was nearly equal to that in NE3, which delivers larger area for permeation of drug in to skin.

The polydispersity index of the formulations is given in Table 4. Polydispersity index of the optimized formulations NE2, NE3, and NE5 were low, with the index values of $0.21 \pm 0.03,0.34 \pm 0.05$, and $0.29 \pm 0.08$, respectively, as compared to the polydispersity index of formulations NE1 and NE4, which had a value of $0.87 \pm 0.12$ and $0.89 \pm 0.18$, respectively. The relatively low polydispersity values of formulations NE2, NE3, and NE5 indicate homogeneity in the droplets size within each formulation.

A literature survey revealed that negatively charged NE with a zeta potential of $-30 \mathrm{mV}$ or lower exhibit moderate to excellent physical stability. ${ }^{22,31,33}$ The zeta potential helps to repulse adjacent similarly charged particles in the system. A higher zeta potential values lower aggregation of droplets and indicate stable in the solution. Zeta potential of the prepared NEs and its NE-gels are given in Table 4-5. The stability study supports the fact that the values of zeta potential correlate with the stability of more stable formulations NE2 $(-22.50 \pm 0.15 \mathrm{mV})$ and NE3 $(-23.20 \pm 0.52 \mathrm{mV})$. Whereas in NE-gel form the zeta potentials NEG1(-25.20 $\pm 0.12 \mathrm{mV})$ and NEG2($22.20 \pm 0.02 \mathrm{mV}$ ) are nearly closed to its NEs as given in Table 5. The viscosity of optimized NE-gels forms are more viscous than ints NEs given in Table 5. The viscosity of formulations increased significantly after the addition of 1\% w/v Carbopol 934. Additionally, the mean droplet size decreased with an increase in the concentration of the $S_{\text {mix }}$, which consequently increased viscosity. ${ }^{34} \mathrm{~A} 1 \% \mathrm{w} / \mathrm{v}$ Carbopol 934 helps the formulations to adhere to the skin for longer and to be more suitable for skin application.

The refractive index of NEs was in the range of $1.11 \pm 0.03$ to $1.93 \pm 0.05$ value close to refractive index of water (1.33) that indicates an isotropic nature of all the formulations. This is further evidence that the NEs are of the $\mathrm{o} / \mathrm{w}$ type. Thus, NEs were both physically and chemically stable without interactions between NE components and the drug. 
Table 5: Nanoemulsion gels droplet size, zeta potential viscosity and spreadability of nanoemulsion gel.

\begin{tabular}{|c|c|c|c|c|}
\hline 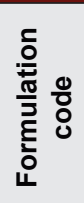 & 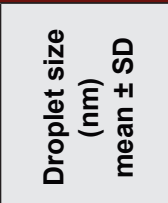 & 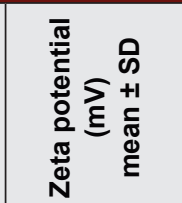 & 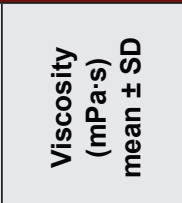 & 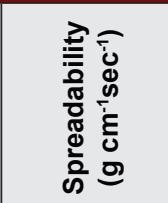 \\
\hline IEG1 & 0.88 & $-25.20 \pm 0.12$ & 119.2 & 18. \\
\hline $\mathrm{EG} 2$ & $73 \pm 0.58$ & $-22.20 \pm 0.02$ & 98.54 & 0.45 \\
\hline NEG3 & $79.65 \pm 0.36$ & $-15.50 \pm 0.53$ & $100.32 \pm 0.55$ & $09.33 \pm 0.51$ \\
\hline
\end{tabular}

Values represented as mean \pm standard deviation (SD), $n=3$

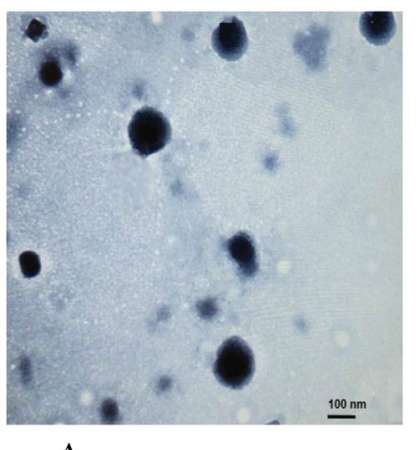

$\mathbf{A}$

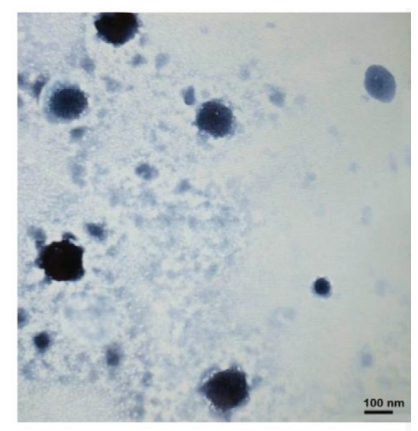

B
Figure 5: Transmission Electron Microscopy of: (A) Nanoemulsion, (B) Nanoemulsion-gel.

The spreadability of NE-gels NEG1, NEG2, and NEG3 were $18.76 \pm 0.37,18.35 \pm 0.45$, and $09.33 \pm 0.51 \mathrm{~g} \mathrm{~cm}^{-1} \mathrm{~s}^{-1}$, respectively are given in Table 5 , which is in accordance with the literature data. ${ }^{35}$ Formulations NEG1 and NEG2 had a much higher spreadability than the NEG3 formulation and were therefore selected for further study.

TEM images were conducted to determine the surface morphology of NE and NE-gels as shown in Figure 5. After microscopic observation of the droplets, the prepared formulations are oil surrounded by water molecules. TEM image showed the presence of spherical non-aggregated droplets within nanorange size. The droplets appear darker area signifies the embedded of raloxifene hydrochloride.

On the consequence of above finding oil-in-water NE and NE-gel system became a very important option for hydrophobic drug RLX, because it can't be easily delivered to the biological system. NE-gel form was formulate to counteract the low viscosity problem of NE which restricts their topical application. Nanosize droplets rapidly penetrate and deliver the drug to the deeper skin layer. ${ }^{12,36}$

\section{Ex vivo permeation and permeability profile}

The ex vivo permeation profiles of RLX were performed to compare the release of RLX from NEs (NE1-NE5)

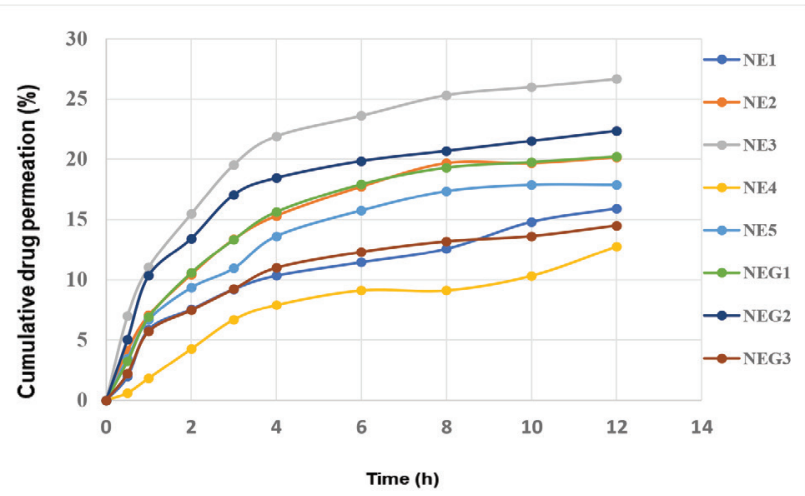

Figure 6: Ex vivo permeation profile of raloxifene from five different nanoemulson formulations NE1-NE5 and three different nanoemulsion-gel formulations NEG1-NEG3.

Table 6: Ex-vivo permeability parameters of NEs (NE1-NE5) and NE-gels (NEG1-NEG3).

\begin{tabular}{|c|c|c|}
\hline $\begin{array}{c}\text { Formulation } \\
\mathbf{c o d e}\end{array}$ & $\begin{array}{c}\text { Flux }\left(\boldsymbol{\mu g} \mathbf{~ c m}^{-2}\right. \\
\left.\mathbf{h}^{-1}\right) \pm \text { SD }\end{array}$ & $\begin{array}{c}\text { Permeability coefficient } \\
\left(\mathbf{c m ~ h}^{-1}\right) \pm \text { SD }\end{array}$ \\
\hline NE1 & $8.18 \pm 0.1$ & $0.019 \pm 0.001$ \\
\hline NE2 & $10.38 \pm 0.3$ & $0.021 \pm 0.002$ \\
\hline NE3 & $16.28 \pm 0.7$ & $0.023 \pm 0.003$ \\
\hline NE4 & $3.25 \pm 0.5$ & $0.016 \pm 0.001$ \\
\hline NE5 & $8.85 \pm 0.3$ & $0.020 \pm 0.002$ \\
\hline NEG1 & $7.57 \pm 0.1$ & $0.015 \pm 0.001$ \\
\hline NEG2 & $11.96 \pm 0.4$ & $0.017 \pm 0.001$ \\
\hline NEG3 & $6.62 \pm 0.1$ & $0.015 \pm 0.001$ \\
\hline
\end{tabular}

Value represented as mean \pm standard deviation (SD), $n=3$, Jss = Steady-state transdermal flux of raloxifene: was calculated by dividing the slope with the diffusion cell area, $\mathrm{Kp}=$ Permeability coefficient: was obtained by dividing Jss with the initial concentration of the drug in the donor cell.

and NE-gels (NEG1-NEG3) all having different quantity of RLX. Figure 6 clearly demonstrate the highest permeation profile was found in NE3 (26.68\%). While, in gel form, the highest permeation was observed in corresponding nanoemulsion-gel NEG2 (22.38\%), suggesting greater skin permeation shown in formulation NE3 and also its corresponding NEG2 (Table 6). This variation was a result of different RLX concentrations in each formulation; RLX solubility was higher in the formulations with higher oil content, thus we conclude that the permeation varies dependent on the RLX solubility in oil and in the $\mathrm{S}_{\text {mix }}$, Additionally, the percentage permeation of RLX increases with time.

The permeability profile of these formulations changes according to the permeation percentage of drug. The flux rate and permeability of RLX highest in NE3 and its gel form NEG2 as given in Table 6. The steady state transdermal flux and permeability co-efficient of NEG2 were obtained $11.96 \pm 0.4 \mu \mathrm{g} \mathrm{cm} \mathrm{ch}^{-2}$ and $0.017 \pm 0.001$ $\mathrm{cm} \mathrm{h}^{-1}$ respectively. From overall advantages over the 


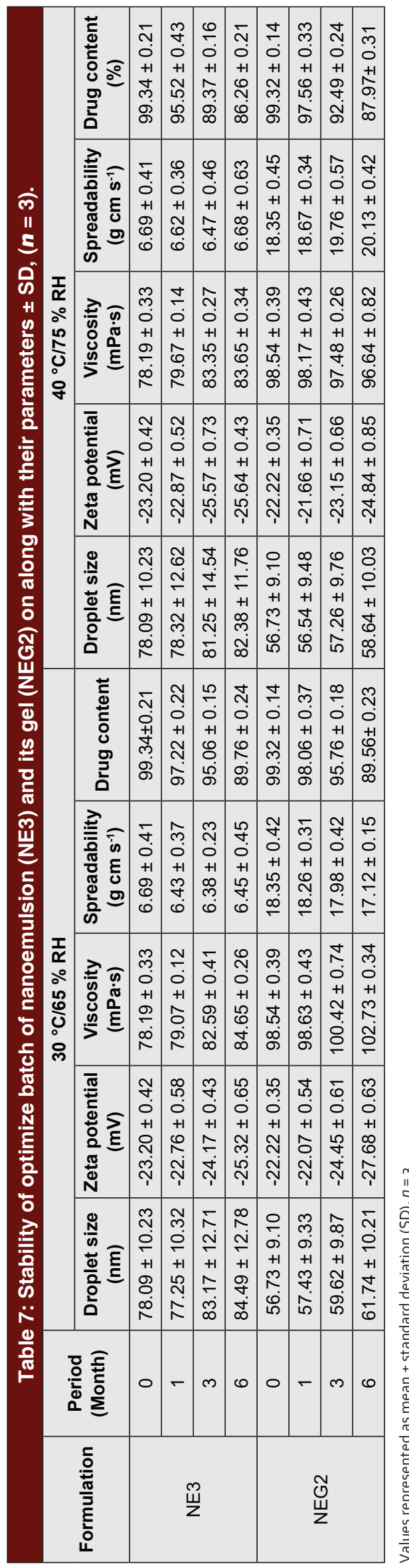

other formulation by avoid first pass metabolism, ${ }^{3}$ direct targetability of drug to the affected area and reduce patient variability. Further more, ex vivo permeation and permeability profile of nanoemulson-gel were maintained for longer period to achive effective therapeutic concentraton in stratum corneum.

\section{Stability Studies}

The result of stability study is shown in Table 7. At the end of study, both the formulations (NE3 and NEG2) were physically stable such as no phase separation occurs eithers by coalescence and creaming by applying centrifugation force at stability conditions $\left(30^{\circ} \mathrm{C} / 65 \% \mathrm{RH}\right.$ and $\left.40^{\circ} \mathrm{C} / 75 \% \mathrm{RH}\right)$. The stability studies of formulations NE3 and NEG2 show slightly increase their droplet size but still below $100 \mathrm{~nm}$, nearly constant zeta potential, and nearly constant viscosity. The drug content of both formulation were satisfactory but show significant reduction more at condition $40{ }^{\circ} \mathrm{C} / 75 \% \mathrm{RH}$. Also, comparatively formulation NE3 form have slightly lesser drug content than its gel form NEG2 at both condtions. Consequently at accelerated condition $40^{\circ} \mathrm{C} / 75 \% \mathrm{RH}$ may attribute small degradation of drug at this condtion which supports the fact that accelerated condition is not a suitable storage condtion for both formulation NE3 and NEG2. But comparatively NEG2 slightly more stable than its nanoemulsion form NE3 in 6 month at same condition that could helpful in maintain the dose of RLX after 6 months. Therefore, it can be concluded that the condtion $\left(30^{\circ} \mathrm{C} / 65 \%\right)$ is more favorable storage condition than $\left(40^{\circ} \mathrm{C} / 75 \% \mathrm{RH}\right)$ for long period of time. Also, on the basis of over all stability studies NEG2 was more stable than NE3 at given conditions.

\section{CONCLUSION}

Nanoemulsion for the topical application of RLX was formulated using the ternary phase diagram method, which was proved by above result and TEM studies. Further the thermodynamic studies proved the formulation was phycially stable. The optimized formulation containing $0.072 \% \mathrm{w} / \mathrm{v}$ raloxifene hydrochloride, 14.29\% v/v Labrafil M2125CS, 33.33\% v/v Smix (Cremophor RH40: Transcutol P, 1:1), and 52.38\% $\mathrm{v} / \mathrm{v}$ distilled water. A gelling agent 1\% w/w Carbopol 934 was added to convert from NE to NE-gel form. Nanoemulsion gel form has prolong adhesive property on the skin surface, better spreading characteristic and high drug dissolving capability, it uphold adequate concentration gradient of drug towards the skin and provide better skin penetration. Such advantages of 
nanoemuslion gel provide the platform for topical delivery. The ex vivo permeation and permeability studies proved that nanoemulsion gel can be used for loading of raloxifene hydrochloride for topical delivery. The entire characterization of optimized formulations were satisfactory in respect of their stability studies. In conclusion, nanoemulsion gel has all the potential to develop an effective, safe and accepted drug delivery system for topical delivery.

\section{ACKNOWLEDGEMENT}

We are thankful to School of Pharmaceutical Sciences, IFTM University, Moradabad for providing the necessary research facilities. The authors would like to thank Cadila Pharma, Ahmedabad, Gujarat, for providing the gift sample of RLX and also, thanks to SD Fine Chemicals, E-Merck, Mumbai. and Gattefosse, India for providing the gift samples of excipients. This work forms a part of research work of Tej Pratap Singh under Gaurav Kumar Jain and Farhan Jalees Ahmad.

\section{CONFLICT OF INTEREST}

The authors declare no conflict of interest.

\section{ABBREVIATIONS}

RLX: Raloxifene hydrochloride; rpm: Revolution per minute; $\mu \mathrm{m}$ : micro meter; $\mathrm{ml}$ : Milli Liter; $\mathbf{n m :}$ Nanometer; hr: Hour; HLB: Hydrophilic Lipophilic Balance; ${ }^{\circ} \mathrm{C}$ : Degree centigrade; $\mathbf{c m}$ : Centimeter; TEM: Transmission Electron Microscopy; mV: Millivolt.

\section{REFERENCES}

1. Hardman MJ, Emmerson E, Campbell L, Ashcroft GS. Selective estrogen receptor modulators accelerate cutaneous wound healing in ovariectomized female mice. Endocrinology. 2008;149(2):551-7. doi: 10.1210/en.2007-1042, PMID 17974625.

2. Elsheikh MA, Elnaggar YSR, Gohar EY, Abdallah OY. Nanoemulsion liquid preconcentrates for raloxifene hydrochloride: optimization and in vivo appraisal. Int J Nanomedicine. 2012;7:3787-802. doi: 10.2147/IJN.S33186, PMID 22888234.

3. Thakkar H, Nangesh J, Parmar M, Patel D. Formulation and characterization of lipid-based drug delivery system of raloxifene-microemulsion and selfmicroemulsifying drug delivery system. J Pharm Bioallied Sci. 2011;3(3):442-8. doi: 10.4103/0975-7406.84463, PMID 21966167

4. Hardman MJ, Ashcroft GS. Estrogen, not intrinsic aging, is the major regulator of delayed human wound healing in the elderly. Genome Biol. 2008;9(5). doi: 10.1186/gb-2008-9-5-r80.

5. Mahdavian Delavary BM, van der Veer WM, van Egmond M, Niessen FB, Beelen RHJ. Macrophages in skin injury and repair. Immunobiology. 2011;216(7):753-62. doi: 10.1016/j.imbio.2011.01.001, PMID 21281986.

6. Mukai K, Urai T, Asano K, Nakajima Y, Nakatani T. Evaluation of effects of topical estradiol benzoate application on cutaneous wound healing in ovariectomized female mice. PLOS ONE. 2016;11(9):e0163560. doi: 10.1371/journal.pone.0163560, PMID 27658263.
7. Puro D, Athawale R, Pandya A. Design, optimization and characterization of nanostructured lipid carriers of raloxifene hydrochloride for transdermal delivery. NANOASIA. 2018;10(1):57-67. doi: 10.2174/22106812086661811 06124337.

8. Chen H, Mou D, Du D, Chang X, Zhu D, Liu J, Xu H, Yang X. Hydrogelthickened microemulsion for topical administration of drug molecule at an extremely low concentration. Int J Pharm. 2007;341(1-2):78-84. doi: 10.1016/j.ijpharm.2007.03.052, PMID 17570625.

9. Shafiq-un-Nabi S, Shakeel F, Talegaonkar S, Ali J, Baboota S, Ahuja A, et al. Formulation development and optimization using nanoemulsion technique: $A$ technical mote. AAPS PharmSciTech. 2007;8(2):1-6.

10. Singh Y, Meher JG, Raval K, Khan FA, Chaurasia M, Jain NK, Chourasia MK. Nanoemulsion: concepts, development and applications in drug delivery. J Control Release. 2017;252:28-49. doi: 10.1016/j.jconrel.2017.03.008, PMID 28279798.

11. Khurana S, Jain NK, Bedi PMS. Nanoemulsion based gel for transdermal delivery of meloxicam: physico-chemical, mechanistic investigation. Life Sci. 2013;92(6-7):383-92. doi: 10.1016/j.lfs.2013.01.005, PMID 23353874.

12. Baibhav J, Gurpreet S, Rana A, Seema S, Vikas S. Emulgel: A comprehensive review on the recent advances in topical drug delivery. Int Res J Pharm. 2011;2(11):66-70.

13. Elnaggar YSR, El-Massik MA, Abdallah OY. Self-nanoemulsifying drug delivery systems of tamoxifen citrate: design and optimization. Int J Pharm. 2009;380(1-2):133-41. doi: 10.1016/j.ijpharm.2009.07.015, PMID 19635537.

14. Shakeel F, Baboota S, Ahuja A, Ali J, Aqil M, Shafiq S. Nanoemulsions as vehicles for transdermal delivery of aceclofenac. AAPS PharmSciTech. 2007;8(4):E104. doi: 10.1208/pt0804104, PMID 18181525.

15. Azeem A, Rizwan M, Ahmad FJ, Iqbal Z, Khar RK, Aqil M, Talegaonkar S. Nanoemulsion components screening and selection: A technical note. AAPS PharmSciTech. 2009;10(1):69-76. doi: 10.1208/s12249-008-9178-x, PMID 19148761.

16. Kadu PJ, Kushare SS, Thacker DD, Gattani SG. Enhancement of oral bioavailability of atorvastatin calcium by self-emulsifying drug delivery systems (SEDDS). Pharm Dev Technol. 2011;16(1):65-74. doi: 10.3109/10837450903499333, PMID 20088679.

17. Gupta S. Biocompatible microemulsion systems for drug encapsulation and delivery. Curr Sci. 2011;101(2):174-88.

18. Date AA, Nagarsenker MS. Design and evaluation of self-nanoemulsifying drug delivery systems (SNEDDS) for cefpodoxime proxetil. Int J Pharm. 2007;329(1-2):166-72. doi: 10.1016/j.ijpharm.2006.08.038, PMID 17010543.

19. Salim N, Basri M, Abdullah DK, Basri H. Phase Behaviour, Formation and Characterization of Palm-Based Esters Nanoemulsion Formulation containing Ibuprofen. J Nanomedic Nanotechnol. 2011;02(4). doi: 10.4172/2157-7439.1000113.

20. Sharma P, Mittal A, Bajpai M. A study of oleic acid oily base for the tropical delivery of dexamethasone microemulsion formulations. Asian J Pharm. 2009;3(3):208-14. doi: 10.4103/0973-8398.56299.

21. Baboota S, Shakeel F, Ahuja A, Ali J, Shafiq S. Design, development and evaluation of novel nanoemulsion formulations for transdermal potential of celecoxib. Acta Pharm. 2007;57(3):315-32. doi: 10.2478/v10007-007-0025-5, PMID 17878111.

22. Laxmi M, Bhardwaj A, Mehta S, Mehta A. Development and characterization of nanoemulsion as carrier for the enhancement of bioavailability of artemether. Artif Cells Nanomed Biotechnol. 2015;43(5):334-44. doi: 10.3109/21691401.2014.887018, PMID 24641773.

23. Chen H, Chang X, Du D, Li J, Xu H, Yang X. Microemulsion-based hydrogel formulation of ibuprofen for topical delivery. Int J Pharm. 2006;315(1-2):52-8. doi: 10.1016/j.jpharm.2006.02.015, PMID 16600540.

24. Rhee YS, Choi JG, Park ES, Chi SC. Transdermal delivery of ketoprofen using microemulsions. Int J Pharm. 2001;228(1-2):161-70. doi: 10.1016/ s0378-5173(01)00827-4, PMID 11576778.

25. Sakeena MHF, Elrashid SM, Munavvar AS, Azmin MN. Effects of oil and drug concentrations on droplets size of palm oil esters (POEs) nanoemulsion. J Oleo Sci. 2011;60(4):155-8. doi: 10.5650/jos.60.155, PMID 21427510.

26. Mehta SK, Kawaljit BK, Bala K. Phase behavior, structural effects, and volumetric and transport properties in nonaqueous microemulsions. Phys Rev E. 1999;59(4):4317-25. doi: 10.1103/PhysRevE.59.4317. 
AW, Kotta S, Ansari SH, Sharma RK, Kumar A, Ali J. Formulation development, optimization and evaluation of aloe vera gel for wound healing Pharmacogn Mag. 2013;9(Suppl 1):S6-S10. doi: 10.4103/0973-1296.117849, PMID 24143047.

28. Chakole CM, Shende MA, Khadatkar SN. Formulation and evaluation of novel combined halobetasol propionate and fusidic acid ointment. Int J ChemTech Res. 2009;1(1):103-16.

29. Sajid M, Sarfaraz M, Alam N, Raza M. Preparation, characterization and stability study of dutasteride loaded nanoemulsion for treatment of benign prostatic hypertrophy. 2014;13(April 2013):1125-40.

30. Buya $A B$, Beloqui $A$, Memvanga $P B$, Préat V. Self-nano-emulsifying drugdelivery systems: from the development to the current applications and challenges in oral drug delivery. Pharmaceutics. 2020;12(12):1-52. doi: 10.3390/pharmaceutics12121194, PMID 33317067.

31. Modi JD, Patel JK. Nanoemulsion-based gel formulation of aceclofenac for topical delivery. 2011;1(1):6-12.

\section{PICTORIAL ABSTRACT}

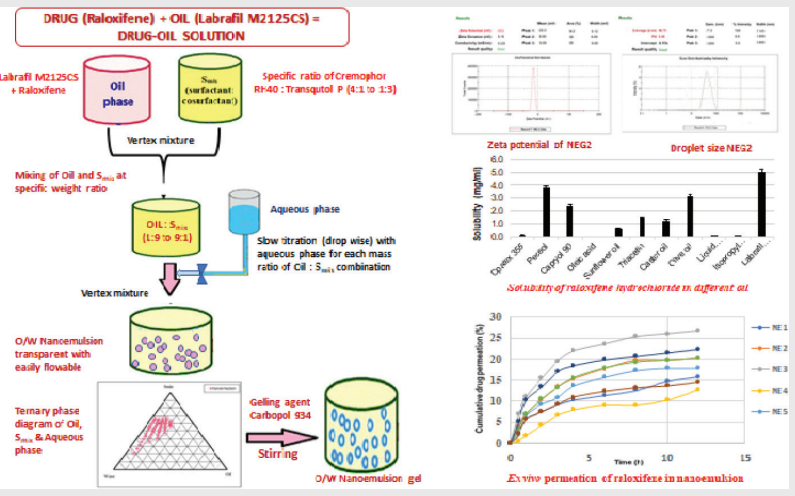

About Authors

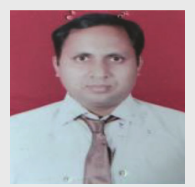

Mr. Tej Pratap Singh, School of Pharmaceutical Sciences IFTM University, Moradabad, Uttar Pradesh, 244102, India.

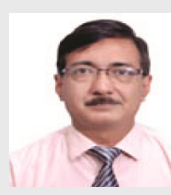

Dr. Farhan Jalees Ahmad, Department of Pharmaceutics, School of Pharmaceutical Education and Research, Jamia Hamdard, New Delhi, India.

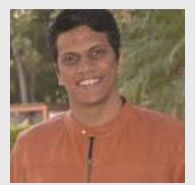

Dr. Gaurav Kumar Jain, Department of Pharmaceutics, Delhi Pharmaceutical Science and Research University, New Delhi, India.

Dr. Navneet Verma, Department of Pharmaceutics, Pharmacy Academy, IFTM University, Moradabad, Uttar Pradesh, 244102, India.
32. Kawakami K, Yoshikawa T, Moroto Y, Kanaoka E, Takahashi K, Nishihara Y, Masuda K. Microemulsion formulation for enhanced absorption of poorly soluble drugs. I. Prescription design. J Control Release. 2002;81(1-2):65-74. doi: 10.1016/s0168-3659(02)00049-4, PMID 11992679

33. Sosnowska K, Szymańska E, Winnicka K. Nanoemulsion with clotrimazole - Design and optimalization of mean droplet size using microfluidization technique. Acta Pol Pharm. 2017;74(2):519-26. PMID 29624257.

34. Tadros T, Izquierdo P, Esquena J, Solans C. Formation and stability of nanoemulsions. Adv Colloid Interface Sci. 2004;108-109:303-18. doi: 10.1016/j. cis.2003.10.023, PMID 15072948.

35. Hussain A, Samad A, Singh SK, Ahsan MN, Haque MW, Faruk A Ahmed FJ. Nanoemulsion gel-based topical delivery of an antifungal drug: in vitro activity and in vivo evaluation. Drug Deliv. 2016;23(2):642-47. doi: 10.3109/10717544.2014.933284, PMID 25013957.

36. Sutradhar KB, Amin L. Nanoemulsions: increasing possibilities in drug delivery. Eur J Nanomed. 2013;5(2):97-110.

The main objective of present research is to formulate and characterize nanoemulsion-based gel of raloxifene for topical delivery using Labrafil M2125CS as oil, Cremophor RH40 as surfactant, Transcutol P as cosurfactant, and Carbopol 934 as gelling agent. Selection of components based on the maximal solubility of raloxifene and maximal emulsification efficacy of surfactant and cosurfactant in oil. The ternary phase diagrams were obtained by the aqueous titration method and Ternary phase diagrams were constructed from the obtained titration values with axes representing phase components. The all characterization of optimized nanoemulsions and their gel exhibit good stability and exvivo permeation of raloxifene. Nanoemulsion-based gel (NEG2) is more selective for topical delivery of raloxifene hydrochloride.

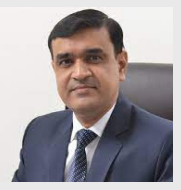

Cite this article: Singh TP, Ahmad FJ, Jain GK, Verma N. Formulation Development and Characterization of Nanoemulsion-based Gel for Topical Application of Raloxifene Hydrochloride. Indian J of Pharmaceutical Education and Research. 2021;55(4):996-1007. 